\title{
Review of Agricultural Supportive Polices in China
}

\author{
Zhi-zhi SI, Feng-ying Nie \\ Agriculture Information Institute, CAAS/Key Lab of Digital Agricultural Early Warning Technology, Ministry \\ of Agriculture/Key Lab of Digital Agricultural Early Warning Technology and System, CAAS, Beijing \\ 100081, China.
}

Correspondence to: Zhi-zhi SI

ABSTRACT: This paper reviewed the changes of agricultural supportive polices in China, analyzed the impact on farmer, rural and agricultural development, and further proposed the development trend of supportive polices in the future.

KEYWORD: Supportive police; Agricultural development; Farmer.

\section{INTRODUCTION}

From the beginning of the 21 st century, "San Nong" issues (agriculture, farmer and rural) became the emphasis of the central government. New polices are applied based on the following principles: the secondary industry supports agriculture; urban economy supports rural economy; and greater support rather than taxation for agriculture. Support for agriculture has also risen significantly. Government spending in "San Nong" covers a large array of areas including supportive spending in agricultural production, subsidies to farmers' income and expenditure in rural social affairs such as education, culture, sanitation and healthcare. Government spending in "San Nong" even covers the development of infrastructure such as rural roads, forests and drinking water facilities.

From 2006 to 2013, "San Nong" expenditure in China increased from 351.7 billion RMB to 1379.9 billion RMB. Calculated at annul increased rate of $11.4 \%$.

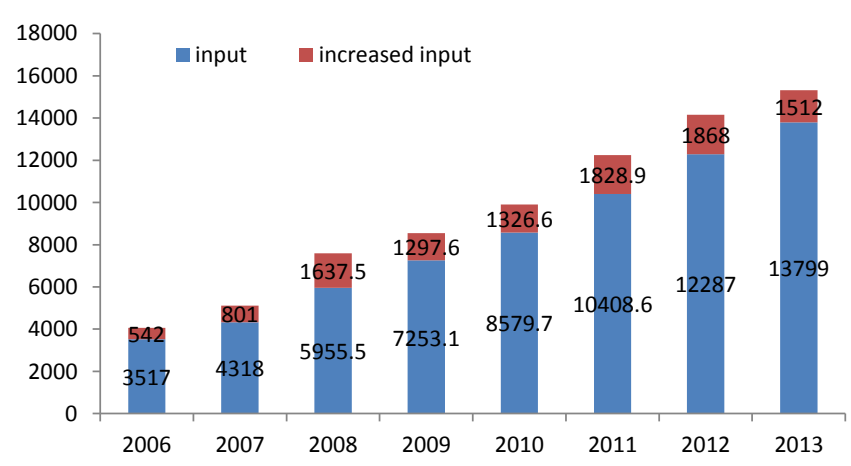

Figure 1 "San Nong” Expenditure in China in recent years
Before 2006, "San Nong" spending covered five main areas. These included rural production expenditure and operating expenses for agriculture, forestry, water and meteorology, capital construction, rural science and technology, disaster relief, and other comprehensive countryside development measures such as rural primary and middle school education and rural tax subsidies. After 2006, government fiscal expenditure on "San Nong" issues was readjusted. The new classification mainly covers three expenditures: rural production and various agro-related operating expenses, the four main subsidy policies and rural social affairs and development.

\section{SUPPORTIVE POLICES REVIEW}

\subsection{Price Support}

Since 2004, food prices have faced downward pressure significantly with grain harvest for several years. After the establishment of a free grain trading market and the freedom to set prices, the policies surrounding minimum purchasing prices were reformulated to exercise macro-control on the basis of the market mechanism. To protect farmers' benefits, ensure grain supply and national food security, the central government applied a minimum purchasing price policy to specific agricultural products. In 2004 a minimum purchasing price for rice was issued and was officially put into effect in 2005. A similar policy was applied to wheat in 2006. China has introduced a policy for purchasing grains at a minimum price for rice and wheat in major crop producing areas, the price being fixed before sowing. In the application period (normally harvesting time), when the market price is lower than the minimum 
purchase price, government authorities purchase grain at the minimum purchase price. When the market price is higher the program remains dormant or is withdrawn. The state-owned China Grain Reserves Corporation is obliged to make intervention purchases if the market price dips below the established support level for three consecutive days.

\subsection{Subsidy Policy}

\subsubsection{Direct payments for grain production}

From 1999 to 2003 China's total grain output declined. This alarmed the central government and from 2004 it began to apply direct subsidies to farmers growing grain. This policy was intended to encourage farmers to produce and stabilize the production of grain through compensating for increases in the cost of grain farming and ensuring reasonable benefits for grain producing farmers.

The subsidy covers machines in 12 categories and 38 sub-categories. It is provided to purchase farm machinery (at 30 percent of the purchase price) with a cap of 50,000 RMB for a single piece and 120,000 in particular cases. Farmers receive a discounted price with the price difference settled between the government and suppliers. Central fiscal spending for the farm machinery purchase subsidy was increased from 0.07 billion RMB in 2004, the first year of policy implementation, to 13 billion RMB in 2009. In 201015.49 billion RMB was budgeted for this program.

\subsubsection{Comprehensive subsidies for agricultural inputs}

The central government began to provide general subsidies for agricultural inputs as a result of increasing price fluctuations for agricultural inputs since 2006. This subsidy in order to reduce production costs and relieve the effects of price hikes associated with agricultural input materials on grain production, such as diesel for farming, fertilizer, pesticides, plastic sheeting and other materials. The total number of subsidies is constantly increasing and these subsidies amounted to 12 billion and 27.6 billion RMB in 2006 and 2007 respectively. In 2008, as fertilizer and diesel prices continued to increase, additional government investment accumulated to 71.6 billion RMB. A dynamic adjustment mechanism applied to this policy since 2009 means that the measure should provide constant support and adjust to changes in the price of fertilizer and diesel for farming. Subsidy funds existed at 79.5 and 83.5 billion RMB (at budgeted figures) respectively in 2009 and 2010.

\subsubsection{Farm machinery purchase subsidy}

This subsidy provides specific funding towards farm machinery purchases in order to encourage farmers to use modern agricultural machinery, promote agricultural mechanization, comprehensively improve productivity, improve agricultural production efficiency, save costs and increase income. The subsidy covers machines in 12 categories and 38 sub-categories. It is provided to purchase farm machinery (at 30 percent of the purchase price) with 50,000 RMB for a single piece and 120,000 in particular cases. Farmers receive a discounted price with the price difference settled between the government and suppliers. Central fiscal spending for the farm machinery purchase subsidy was increased from 0.07 billion RMB in 2004 which is the first year, to 13 billion RMB in 2009. In 2010 15.49 billion RMB was budgeted for this program.

\subsubsection{Improved varieties subsidy}

To encourage coverage of improved crop varieties, accelerate their extension, establish structure in the rural economy, standardize production and management and merchandize sales, subsidies for improved varieties were applied to soybean, wheat, rice, maize, cotton, rapeseed, highland barley, peanuts and potatoes from 2002.The range of this subsidy has expanded constantly. Subsidies for improved varieties of rice, wheat, maize and cotton have achieved nation-wide coverage since 2009. Soybeans are subsidized across the whole of Liaoning, Jilin, Heilongjiang and Inner Mongolia provinces. Rapeseeds are covered in a similar manner in 10 major producing provinces including Jiangsu, Zhejiang and Anhui and in certain areas such as Xinyang (Henan Province) and Hanzhong and Ankang (of Shaanxi Province). Highland barley is covered in all ethnic Tibetan areas including Sichuan, Yunnan, Tibat, Gansu and Qinghai. There is also a pilot programme for peanuts which began in 2010.

\subsection{Agricultural Insurance}

China government launched subsidized pilot agricultural insurance schemes for both livestock and crop producers since 2007. In general, the cost of the insurance premium is shared by the central government, local governments and farmers themselves. The shares vary across commodities and provinces, but on average the proportion covered by the central government subsidy is around $40 \%$, the share of local governments is around one-third and about $20 \%$ of the premium is paid by farmers. Agricultural insurance premium more than 60 billion Yuan during five years, average annual growth rate is $85 \%$. The geographical coverage has progressively increased from 6 provinces in 2007 to 23 in 2010 
and to all provinces and autonomous regions in 2012. Farmers' participation in the scheme is voluntary. There are 18 insurance corporations who are eligible to conduct the scheme. The central government subsidy increased from CNY 2.2 billion (USD 289 million) in 2007 to CNY 14.5 billion (USD 2.3 billion) in 2012.In 2012, agricultural insurance premium scale up to 24.06 billion Yuan, Increased by $38.4 \%$ than last year. It covers 9 Planting varieties including corn, rice, Wheat, cotton, oil crops, sugar crops, potato, highland barley, natural rubber, and 5 animal varieties including reproductive sow, fattening pigs, dairy cow, yak and Tibetan sheep.

\subsection{Resources and environment protection}

\subsubsection{Conversion of cropland to forest}

Under the "grain for green project" (officially called the "Returning Farmland to Forests Program") cultivated lands in environmentally fragile areas are retired from crop production (mainly grains), and converted to pasture or forest. The first pilot test was carried out in Sichuan, Shaanxi and Gansu Provinces in 1999, 25 provinces (autonomous regions and municipalities) were officially involved in 2002. As from 2004, compensation for retired land is paid in cash per unit of land. The period for which "retired" land is subsidized is set at two years for land returned to pasture, five years for land converted to "economic" forests and eight years for land converted to "ecological" forests. Free seedlings are also provided for forestation.

In recent years, there has been a significant slowdown in the conversion rates largely due to growing concerns over grain security. About CNY 200 billion (USD 30 billion) is foreseen to be allocated for this project for 2010-21, but the majority of the funds is to be spent on compensations for already converted land. In 2012, budgetary allocation for this program amounted to CNY 17.6 billion (USD 2.8 billion).

\subsubsection{Conversion of grazing land to grassland}

This policy was first applied in 2003. Grassland fences for eight years were constructed on 778 million mu of pasture, which involved 181 counties and 900 thousand farming households. Accumulative investment from the central government equated to 20.9 billion RMB, of which 1.96 billion RMB was invested in 2008, 3.66 billion in 2009 and approximately 3.2 billion RMB in 2010 . As a result natural ecosystems in project areas have been progressively improving.

Since August 2011, new measures were implemented to improve the policy including the rational distribution of grassland fencing. "Grassland ecological protection" program for eight western provinces was announced in 2011. Its objective is to promote protection of grassland and to enhance incomes of animal herders.

\subsection{Temporary purchase and storage}

The Chinese government has implemented temporary purchase and storage policies for a number of agricultural commodities since 2008. Temporary purchases are accompanied by temporary storage measures for the sake of food security and cover rice, maize, soybean, rapeseed, sugar and pork. Among these chosen products, some are closely related to national food security (such as rice which is a main staple food in China), have an important impact on market supply and stability (such as maize, used as a feed grain, and pork), or are subject to a highly open market with sizeable imports (such as soybeans, cotton and rapeseed). The objectives of the policy are to fend off risks upon farmers' income and domestic market stability in the case of wild fluctuations in agricultural product prices. The program, implemented primarily in the interests of food security, has a limited impact upon price since the quantity of purchased and stored commodities amount to far less than domestic production, and this program can also be considered a public reserve instrument for food security.

\section{IMPACT OF AGRICULTURAL SUPPORTIVE POLICES}

\subsection{Further strengthen on agricultural comprehensive production capacity and agricultural products supply}

Supportive polices to farmers continuously strengthen, it is benefit to agricultural and rural economic development faced with many favorable conditions. In 2011, gross output value of agriculture is 280.386 billion Yuan, $11.2 \%$ higher than previous year. The added value of agriculture totaled 4.7712 trillion Yuan, $4.5 \%$ higher than a year ago. The contribution of agricultural growth to national economy growth is $10.2 \%, 2.6 \%$ higher than previous year. Grain Production capacity constantly improved, annual grain production is $\mathbf{5 7 1 . 2 1}$ million tons, 24.73 million tons over the last year, $4.5 \%$ above a year ago, more than 500 million tons for five consecutive years. In 2013, ten consecutive years of increased production is expected to achieve. Output of cotton, oilseeds and sugar-bearing crops, fruits, vegetables, tea, meat, eggs, milk and aquatic products all registered growth in 2011.all these products had ample market supply. Farm product quality and safety levels were steadily elevated and major animal diseases were roughly under control. The achievements contributed to improving people's 
livelihood and maintaining social stability and harmony.

\subsection{Farmers get better income and fewer burdens}

After several years' effort, the taxes and fees reform reduced farmers burden, effectively promoted the restorative growth of farmers' income. The number and amount of national subsidies program to agricultural production increased, not only reduced the farmer's production costs, but also increased production enthusiasm. In 2011, the Direct payments for grain production and Comprehensive subsidies for agricultural inputs, average subsidies nearly 60 Yuan per mu, effectively relieved the impact of agricultural materials prices on farmers, stabilized grain farmers' income, aroused the enthusiasm of farmers. Under the policies of Subsidies for improved crop varieties, improved crop varieties supporting technology speed up, obviously improved the technological content of grain production, effectively promoted the standardization of agricultural production and regional distribution. Under the subsidy of Farm machinery purchase subsidy, the speed of agricultural mechanization process further accelerated. In 2011, agricultural machinery grosses power more than $5 \%$ over last year. The national comprehensive mechanization level increased 2.5 percent.

Per capita net income of rural residents is average 6,977 Yuan in 2011, the real growth rate was $11.4 \%$. Rural residents' income growth rate higher than the urban residents, the relative gap between the urban and rural residents continued to shrink, but the absolute gap is still growing. The per capita net income of rural residents is $11.4 \%$ over the previous year, while per capita net income of urban residents is $8.4 \%$ over the previous year. The growth rate of rural residents was 3.0 percentage points higher than urban residents. Average per capita net income from household production was 3222 Yuan, $13.7 \%$ over the last year. The growth rate was 1.6 percentages higher than the previous years. Household production in the primary industry brought on average 2520 Yuan in net income to rural residents.

\subsection{Improvement of supportive agricultural polices}

The level of total agricultural support has increased distinctly in the past decade; however agricultural support is very low in per capita terms. Although many policies aim to increase farmers' income and improve their rural livelihood, the level of support is still very low in per capita terms. In 2010, transfer income gained by the rural household was $453 \mathrm{RMB}$ (67 USD) per capita. Even calculated with the overestimated figures in China's notification to the WTO the per capita amount available to a single rural household that falls into the amber and green box is still minimal with 3727 RMB (536 USD) in 2008, compared with UN (152,986 USD) and EU( 14130 Euro), much lower in comparison with developed countries. The contribution given with the purpose of increasing farmers' income per capita is significantly lower than the practical effects of increasing grain prices. It is difficult for farmers to consider subsidies as a major deciding factor in making decisions about future grain production.

The design of the existing agricultural policy system is still relatively preliminary. There are inevitably some problems in implementing current policies. Due to regional differences in the level of agricultural development and policy implementation there are inconsistencies in both the effects and objectives of policies. In this context direct payments for grain production become the most debatable measures. Such as, crop production decisions are not associated with the subsidy amount. The role of direct crop subsidies and comprehensive agricultural inputs subsidies has shifted from boosting food production by the mobilization of farmers' enthusiasm for growing grain to purely income support for farmers. Controversy still exists at home and abroad largely because of the policy implementation differences and lack of coordination when setting goals. However, there is reason to believe that China's agricultural domestic policy system will be more efficient and effective under the WTO framework with the help of continuous improvements and further reform. In the future, with the development of the economy and overall national strength, more support will be provided to agriculture.

\section{CONCLUSION}

In recent years, China's agricultural domestic support level has improved rapidly. It has played a positive role to promote the development of agriculture, ensure food security and farmers' livelihood. The level of total agricultural support has increased distinctly in the past decade, but agricultural support is very low in per capita terms. Improvement of supportive agricultural polices is not only ensure development of China's agriculture, but also food security in the world.

\section{REFERENCES}

[1] Jikun Huang, Xiaobing Wang and Huanguang Qiu, Smallscale farmers in China in the face of modernisation and globalisation.

[2] Li Wei, A study on China's Agrarian Institutional Change.2013, China development press, 2011.6.

[3] Agricultural Policy Monitoring and Evaluation 2013. OECD Countries and Emerging Eco nomies.2013.117-130. 